\title{
'Por Entre os Canteiros' - Um Estudo Sobre a Presença das Mulheres na Construção Civil
}

\author{
'Among the Sites' - A Study on the Presence of Women in Construction
}

\author{
Mayra Rachel da Silva \\ Universidade Estadual do Ceará \\ rachelsilva-ce@hotmail.com \\ Maria do Socorro Ferreira Osterne \\ Universidade Estadual do Ceará \\ rachelsilva-ce@hotmail.com
}

\section{Resumo}

$\mathrm{Na}$ contemporaneidade, novas configurações se apresentam ao mundo do trabalho. Profissões, culturalmente constituídas no imaginário social como específicas da condição masculina estão sendo ocupadas crescentemente por mulheres, a exemplo, podemos citar o aumento da participação feminina como mão de obra na construção civil. Nesse sentido, o presente trabalho tem por objetivo apresentar os aspectos das relações de gênero e trabalho que permeiam o desempenho das atividades de homens e mulheres na construção civil de Fortaleza. Esta pesquisa apresenta natureza qualitativa e é do tipo bibliográfica e de campo ${ }^{1}$.

Palavras-chave: Gênero; Divisão sexual do trabalho; Construção civil.

\begin{abstract}
Nowadays, new settings are present in the world of work. Jobs that are culturally associated in the social imaginary as malespecific activities are being increasingly pursued by women; for instance, there is an increase in female participation as labors in the building trade. Accordingly, this study aims to investigate which aspects of gender relations permeate the work and performance of men and women in the building trade of the city of Fortaleza. This is a qualitative research, and it recurs both to bibliographical and field inquiries.
\end{abstract}

Keywords: Gender; Sexual division of labor; Construction. 


\section{Introdução}

A presença das mulheres na força de trabalho brasileira vem aumentando consistente e significativamente nas últimas décadas, principalmente a partir dos anos 1970.

Além de mudanças quantitativas, a inserção feminina no mundo do trabalho sofreu alterações de ordem qualitativa, ou seja, as mulheres passaram a ocupar os mais diversos postos de trabalho. Embora, de um lado, uma minoria delas exerça cargos de prestígio e, de outro, uma maioria, encontrese na informalidade e nas atividades mais precárias, sem qualquer proteção das leis trabalhistas.

Neste contexto de mudanças, registramos a presença das mulheres em funções antes exercidas, majoritariamente, por homens. Esse é o caso da construção civil de Fortaleza, Ceará, cuja participação da mão de obra feminina começou a tomar forma na década de 1990, sendo intensificada nos anos 2000.

Apesar desse tema encontrar-se em voga na mídia cearense, não encontramos nenhum estudo científico referente à presença das trabalhadoras no setor da produção desse ramo produtivo. Fato que torna evidente a importância dessa pesquisa para os estudos relacionados ao gênero e ao trabalho.

Buscamos, através de nossas análises, verificar quais aspectos das relações de gênero e trabalho permeiam o desempenho das atividades de homens e mulheres na construção civil de Fortaleza, Ceará. Procuramos, dentre outros objetivos, compreender os motivos apresentados pelas mulheres para justificar sua entrada neste setor e, ainda, perceber como se expressa a divisão sexual do trabalho nesse segmento produtivo.

\section{Construção Civil: Um Espaço para as Mulheres?}

Atualmente, ao percorrermos as ruas de Fortaleza, Ceará, podemos perceber um aumento significativo no número de obras em execução nesta cidade. Deparamo-nos com obras de mobilidade urbana, de construção de equipamentos públicos, de estádios e de condomínios residenciais. Neste contexto, a verticalização urbana e a especulação imobiliária têm se apresentado de forma intensa nessa capital.

Em meio a tantas edificações, uma cena, antes pouco observada e, há algumas décadas, impossível de ser imaginada, passou a fazer parte deste cenário - a presença das mulheres trabalhando na execução das obras. De acordo com o Sindicato dos Trabalhadores na Indústria da Construção Civil da Região Metropolitana de Fortaleza, Ceará $\left(\right.$ SITCCRMF) ${ }^{2}$, a inserção feminina nesse ramo aconteceu de forma mais intensa a partir do ano de 2010. Entretanto, os informantes, também, registram a participação das mulheres no setor na década de 1990, mais precisamente entre os anos de 1994 e 1995. Segundo o dirigente sindical Lucas $^{3}$ :

As mulheres eram convocadas pra trabalhar na construção civil pelo simples fato de ter que limpar os apartamentos, ou seja, os homens aprontavam todo o apartamento, deixavam sujos lá e as mulheres iam pra limpar os apartamentos. Elas começaram a limpar e o serviço que o homem fazia, por exemplo, pra dar uma noção pras pessoas, que é levantar alvenaria, rebocar, assentar cerâmica e fazer o emassamento, ele ganhava por tudo isso e a mulher vinha, em seguida, pra limpar o apartamento (LUCAS, DIRIGENTE 


\section{SINDICAL)}

Posteriormente, conforme explicam os informantes, na intenção de reduzir os custos nas obras e tendo em vista a falta de mão de obra que se apresentava ao setor, os empresários encontraram na força de trabalho feminina a solução para parte de seus problemas. Nesta perspectiva:

Os empresários perceberam que estavam gastando além do normal ${ }^{4}$. Então, o que eles fizeram? Começaram a contratar mulher para, além da limpeza do apartamento, fazer o emassamento da cerâmica, ou seja, elas faziam uma dupla função e ganhavam um salário só. Então, elas começaram a partir daí. De 2010 pra cá, teve uma inserção maior, por que elas fazem o emassamento, tem umas delas que assenta tijolo, tem umas delas que fazem reboco, tem pedreira. Então, houve uma inserção maior do ano de 2010 pra cá. Por exemplo, hoje tem obra que tem 80 mulheres trabalhando (Timóteo, Dirigente Sindical).
De acordo com a Pesquisa Mensal de Emprego - PME (IBGE, 2012) ${ }^{5}$, no ano de 2011, as mulheres eram maioria na população de 10 anos ou mais de idade, em média, $53,7 \%$. No entanto, elas eram minoria, aproximadamente, $45,4 \%$, na população ocupada.

Com relação à participação das trabalhadoras nos grupamentos de atividade econômica, o Gráfico 1 explana a distribuição da população ocupada feminina nos diversos setores nos anos de 2003 e 2011.

No tocante à presença feminina na construção civil, dados do Ministério do Trabalho e Emprego - MTE (2011) ${ }^{7}$ nos mostram que, no Brasil, o número de trabalhadoras neste setor cresceu $65 \%$ em uma década ${ }^{8}$. No ano de 2000 , elas eram pouco mais de 83 mil entre 1,094 milhão de pessoas empregadas pelo setor. Em 2008, esse número subiu para 137. 969. No primeiro bimestre do ano de 2010, 5.258 mulheres conseguiram emprego na construção civil, ocupando $5,9 \%$ das vagas geradas no setor, nesse período.

Percebemos, ainda, que, no Brasil, iniciativas do Poder Público e da sociedade civil vêm fomentando a inserção feminina,

Gráfico 1 - Participação Feminina da População Ocupada, por Agrupamento de Atividades (\%) - 2003 e $2011^{6}$.

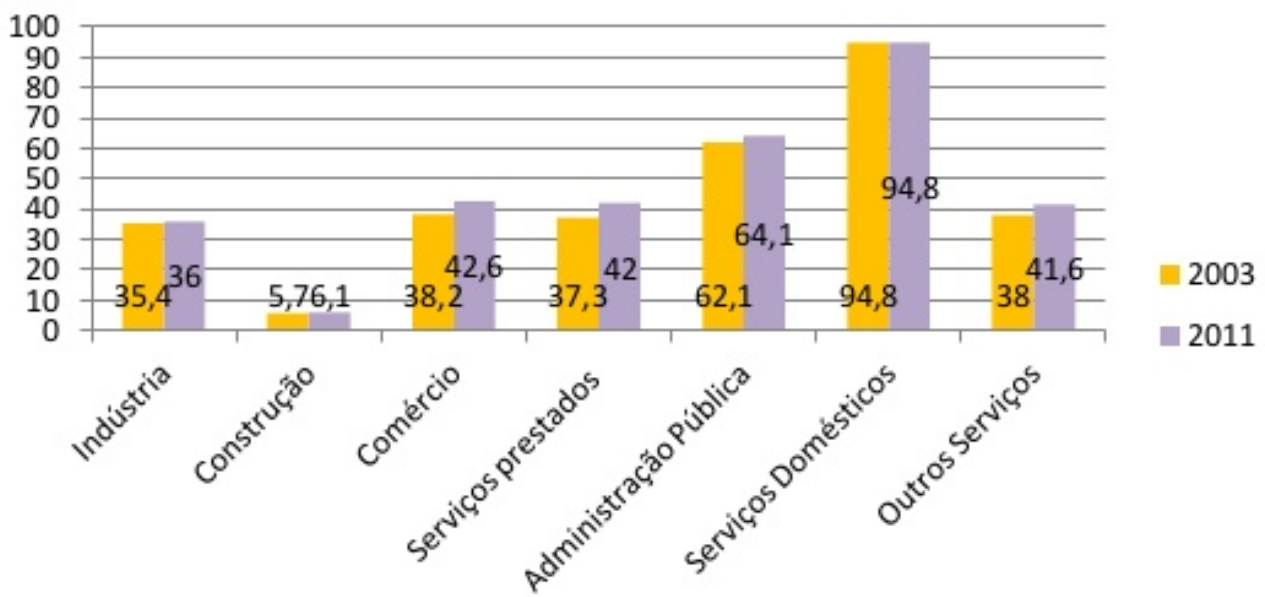

Fonte: IBGE (2012). 
como mão de obra, nesse setor. A exemplo, podemos citar o caso de Fortaleza (CE): em 2007, a Prefeitura executou o Programa Mulheres Pedreiras, através dele foram capacitadas 180 mulheres para trabalhar na construção civil. Vale dizer que grupos de mulheres capacitadas pelo referido programa já trabalharam em obras de conjuntos habitacionais do município e na execução das obras do Hospital da Mulher de Fortaleza (CE).

Outra iniciativa de incentivo à inserção feminina na construção civil foi lançada em 2011, pelo Sinduscon - $\mathrm{CE}^{9}$ em parceria com o Serviço Nacional de Aprendizagem Industrial - SENAI, trata-se do projeto 'Mulheres da Construção', este, por sua vez, visava a capacitação de 100 mulheres para atuar no setor. Os cursos ofertados eram de pedreira, de carpinteira e de instaladora hidráulica e elétrica.

Pelo descrito, podemos verificar a crescente participação feminina nesse segmento, espaço social e culturalmente destinado aos homens. Tão logo, consideramos fundamental 0 desenvolvimento de estudos que ajudem na compreensão dessas novas configurações que se colocam ao mundo do trabalho, pois, sob nosso entendimento, essas mudanças que se apresentam a este ramo produtivo são geradoras de tensões e conflitos e repercutem, mais intensa e negativamente, sobre $\mathrm{o}$ trabalho feminino.

\section{Construção Civil, isso é Coisa de Mulher?}

Para pôr em discussão a presença das mulheres na construção civil, pensamos ser indispensável analisar muito além dos aspectos positivos e negativos decorrentes dessa inserção. Acreditamos ser necessário partir do entendimento de que a presença feminina no âmbito desse setor precisa ser situada no contexto das relações de gênero, ao levarmos em consideração que, social, cultural e historicamente, as obras civis não são reconhecidas como um espaço para a atuação das mulheres. Nesse sentido, tendo como referência a literatura existente e os dados empíricos desta pesquisa, buscamos evidenciar como se mostram as questões de gênero no âmbito desse setor produtivo.

De acordo com Scott (1990), a noção de gênero possui duas partes e várias sub-partes que se encontram interligadas. A primeira parte refere-se à ideia de que o "gênero é um elemento constitutivo das relações sociais baseadas nas diferenças que distinguem os sexos". Enquanto a segunda, vincula-se à premissa de que o "gênero é uma forma primária de relações significantes de poder" (SCOTT, 1997, p. 289).

Quanto às sub-partes, Scott (1990) aponta que elas estão associadas aos símbolos culturalmente disponíveis, que permitem a formação de representações simbólicas (exemplo: Eva e a Virgem Maria). Vinculamse, também, aos conceitos normativos, que interpretam e dão sentido aos símbolos expressos nas doutrinas religiosas, educativas, científicas, políticas ou jurídicas, afirmando enfaticamente o que é masculino e feminino. Estão associadas às instituições e organizações sociais. E, por fim, estão ligadas à identidade subjetiva, que é a maneira, por meio da qual, são construídas as identidades de gênero, relacionando-as com a realidade histórico-social.

Para Louro (1992), enfocar o caráter fundamentalmente social da categoria em epígrafe não significa negar sua dimensão biológica. $\mathrm{Na}$ realidade, esse tipo de compreensão enfatiza a construção social e histórica produzida em decorrência das características biológicas que, frequentemente, se convertem em desigualdades, expressas nos papéis sociais direcionados aos homens e às mulheres.

No desenvolver da pesquisa de campo, 
escutamos, frequentemente, discursos que associam homens e mulheres a trabalhos diferenciados, a partir da concepção que os sujeitos da investigação têm em relação às características inerentes a cada um dos sexos. Ao questionarmos, por exemplo, sobre as atividades que as trabalhadoras desenvolvem melhor pelo fato de serem mulheres, a maioria delas e, também, os homens apontam as tarefas que requerem cuidado, dedicação e zelo como as que são melhor executadas por elas, conforme expressam algumas falas:

No que elas se identificam mais é na limpeza, no emassamento e nesses serviços que são mais pra mulher os detalhes, o acabamento, 'né'?[...] $\mathrm{Na}$ verdade, a mulher ela é mais atenciosa. Tem mais aquele carinho pela profissão. Ela se dedica mais, o homem também se dedica, mas o homem já é um pouco bruto desde que foi gerado. Elas não, já "é mais delicada". Já bota uma massa, já coloca um tijolo, já bate um esquadro, já tem aquele detalhe de olhar para o acabamento e fazer bem. Nisso elas são bem perceptivas (Silas, Pintor, 30 Anos).

Algumas coisas aqui na obra facilita o fato da gente ser mulher, pois sai com mais qualidade. Vamos supor: a vidraça com tinta. $O$ homem não quer saber se vai arranhar, ele quer saber se tira a tinta. Nós já vamos com cuidado de não arranhar a vidraça, de não arranhar o alumínio. A gente tem aquele gosto. A gente faz de conta que é da nossa casa. Sempre a gente coloca na nossa mente um faz de conta, um faz de conta que é meu. O homem não. Não é dele, nem meu, nem teu e fica do jeito que fizer. Eles pensam: ninguém vai ver o arranhão porque 'tá' bonito. Então, a mulher já faz com muito carinho, com qualidade. Ela não quer ver um cisquinho no chão. Uma coisinha acaba a beleza. Um pingo de tinta que tiver no chão, a parede pode estar linda como for, o pingo de tinta, na hora do acabamento, acaba com o trabalho da pintura da parede. A gente tem mais cuidado com a qualidade do acabamento (Sara, Servente, 38 Anos).

Nessa linha de raciocínio, Louro (1992) expõe seu entendimento sobre os papéis sociais. Segundo ela, eles:

[...] seriam, basicamente, padrões ou regras arbitrárias que uma sociedade estabelece para seus membros e que definem seus comportamentos, suas roupas, seus modos de se relacionar ou de se portar. Através do aprendizado de papéis, cada um/a deveria conhecer o que é considerado adequado (e inadequado) para um homem ou para uma mulher numa determinada sociedade, e responder a essas expectativas (LOURO, 1992, p. 24).

Saffioti (1987), ao refletir sobre as relações de gênero, as compreende como construções sociais e históricas constituintes de um sistema simbólico que valora e cria hierarquias, tendo por referência o sexo e os aspectos culturais de um determinado período histórico. Para a autora, os seres humanos nascem machos ou fêmeas, mas é através da educação que se tornam homens e mulheres. Segundo ela, a identidade social dos indivíduos é socialmente construída.

É conveniente salientar que a estudiosa, em destaque, considera que a constituição dos gêneros se dá através da dinâmica das relações sociais e não se trata apenas de 
perceber corpos que entram em relação uns com os outros. É a totalidade formada pelo corpo, pelo intelecto, pela emoção, pelo caráter do 'eu', que estabelece uma relação com o 'outro'. Cada ser humano, portanto, é a história de suas relações sociais, marcadas por antagonismos e contradições de gênero, classe e raça/etnia.

A autora supracitada defende, ainda, a ideia do uso simultâneo do conceito de gênero e patriarcado, pois, em seu entendimento, o patriarcado está "no coração da engrenagem exploração- dominação" (SAFFIOTI, 2004, p. 88).

Segundo Saffioti (2004), o patriarcado traz em seu bojo relações de hierarquia entre seres socialmente diferentes. Desta forma, ele serve como um instrumento para compreensão das desigualdades estabelecidas entre homens e mulheres, nas quais a dominação masculina faz-se sempre presente.

Puleo (1999), por sua vez, considera que a categoria gênero sugere uma teoria da construção social das identidades sexuadas, bem como das relações de poder entre os sexos, isto é, trata-se de uma relação dialética entre os sexos. Para essa estudiosa, discutir sobre a categoria gênero significa, ainda, falar de um conceito elaborado pelas ciências sociais a fim de analisar a constituição sociohistórica das identidades masculina e feminina. Supõe, deste modo, considerar a existência de discursos que legitimam e justificam a hierarquização dos homens e do masculino em relação às mulheres e ao feminino.

Assim, uma análise das relações de gênero passa, necessariamente, por uma reflexão sobre as relações de poder estabelecidas em função do sexo. Para Foucault (2007), por exemplo, o poder está imbricado na sociedade, dissipado em todas as partes das relações sociais, tendo a capacidade de sustentar ou quebrar os sistemas de dominação.
Para o autor em discussão, o poder deve ser analisado como algo que circula, que funciona em cadeia, que nunca está localizado em um único polo e que não pode ser apropriado como riqueza ou bem. Para ele, o poder funciona e se exerce em rede. Os indivíduos, em suas malhas, ao mesmo tempo em que exercem o poder, sofrem sua ação.

Ao refletirmos sobre como funcionam as redes de poder no âmbito da construção civil, mais especificamente quando situamos o exercício do poder no campo das relações de gênero, é possível perceber que, em algumas situações, as mulheres estabelecem, mesmo que inconscientemente, algumas estratégias para conseguir adentrar e se manter nesse espaço masculinizado, fazendo, desta forma, com que o poder circule.

Neste sentido, podemos citar como exemplo as seguintes táticas utilizadas pelas trabalhadoras: tratam o trabalho masculino como importante para o desempenho de sua atividade, sob a intenção de criar um clima de cooperação no canteiro de obra, além disso, comparam as relações de trabalho às relações familiares e, em alguns casos, se utilizam da condição feminina para usufruir de algumas vantagens junto aos homens.

Bourdieu (2001), por sua vez, defende a existência do poder simbólico, através do qual, os campos dominantes são beneficiários de um capital simbólico que, por sua vez, é disseminado e reproduzido por meio de instituições e práticas sociais, que lhes possibilita exercer o poder. Trata-se, portanto, da teoria da dominação simbólica que se expressa, por exemplo, na sobreposição do sexo masculino ao feminino. De acordo com Bourdieu (2007), a dominação masculina encontra suas origens num comportamento histórico de forças materiais e simbólicas atuantes nas esferas pública e privada.

Bourdieu (2001) compreende os símbolos como instrumentos, por excelência, da integração social. Sob essa lógica, relata que 
o trabalho de reprodução da divisão dos gêneros, até recentemente, esteve garantido por três instâncias principais que se encontravam em consonância com os princípios do Estado (que veio ratificar e reforçar os preceitos do patriarcado privado com as de um patriarcado público presente em todas as instituições responsáveis por gerir e regulamentar a existência quotidiana da unidade doméstica), são elas: a Família, a Igreja e a Escola. Estas, sincronizadamente, possuem a característica de agir sobre as estruturas inconscientes, explica o autor:

É, sem dúvida, à Família que cabe o papel principal na reprodução da dominação e da visão masculinas; é na família que se impõe a experiência precoce da divisão sexual do trabalho e da representação legítima dessa divisão, garantida pelo direito e inscrita na linguagem. Quanto à Igreja, (...) ela inculca (ou inculcava) explicitamente uma moral familiarista, completamente dominada pelos valores patriarcais e principalmente pelo dogma da inata inferioridade das mulheres. Por fim, a Escola, mesmo quando já libertada da tutela da igreja, continua a transmitir os pressupostos da representação patriarcal e, sobretudo, os que estão inscritos em suas próprias estruturas hierárquicas, todas sexualmente conotadas (...) (BOURDIEU, 2007, p. 103-4).

$\mathrm{O}$ referido estudioso evidencia que a divisão entre os sexos parece estar na ordem das coisas e é percebida como algo tão natural, ao ponto de ser inevitável. Alerta, também, sobre a necessidade da relação entre os sexos estar reinserida na história com vista a esclarecer como as diversas instituições atuam para ratificar a dominação masculina, pois para ele: aquilo que, na história, aparece como eterno não é mais que o produto de um trabalho de eternização que compete a instituições interligadas tais como a família, a igreja, a escola, e também, em uma outra ordem, o esporte e o jornalismo (...) (BOURDIEU, 2007, p. 8).

No entendimento de Bourdieu (2007), o mundo é socialmente sexuado. A sociedade assume o papel de construir o corpo feminino e o masculino com base numa ordem de oposição, marcada por uma visão androcêntrica, que resulta, na maioria das vezes, em um apreço maior às características atribuídas aos homens:

A primazia universalmente concedida aos homens se afirma na objetividade de estruturas sociais e de atividades produtivas e reprodutivas, baseadas em uma divisão sexual do trabalho de produção e de reprodução biológica e social, que confere aos homens a melhor parte, bem como nos esquemas imanentes a todos os habitus; moldados por tais condições, (...), eles funcionam como matrizes das percepções, dos pensamentos e das ações de todos os membros da sociedade, como transcendentais históricos que, sendo universalmente partilhados, impõem-se a cada agente como transcendentes (BOURDIEU, 2007, p. 45).

A lógica paradoxal da dominação masculina e da submissão feminina só pode ser compreendida quando levados em consideração os efeitos duradouros que a ordem social exerce sobre mulheres e homens. A força simbólica, segundo o autor 
em epígrafe, "é uma forma de poder que se exerce sobre os corpos, diretamente, e como que por magia, sem qualquer coação física, mas essa magia só atua com o apoio de predisposições colocadas, como molas propulsoras, na zona mais profunda dos corpos" (BOURDIEU, 2007, p. 50).

A dominação masculina, nesta compreensão, se estabelece de forma sutil e encontra maior eficácia na medida em que a maioria das mulheres não tem ciência de sua condição de dominada. Essa situação acaba contribuindo para que as mulheres aceitem e, até mesmo, colaborem para efetivação da dominação.

Segundo Berger e Luckmann (1978), os indivíduos se tornam parte da sociedade a partir do momento em que inserem em sua dialética, iniciada através do processo de interiorização. Esta, por sua vez, constitui, primeiramente, a base da compreensão de nossos semelhantes e, em segundo lugar, da apreensão do mundo como realidade social dotada de sentido. Esta apreensão não é decorrente de criações autônomas de significados por indivíduos isolados, mas começa com o fato do indivíduo 'assumir' o mundo no qual os outros já vivem.

Com base nessa prerrogativa, é possível afirmar que mulheres e homens, compreendem o mundo e a si próprios de acordo com símbolos atribuídos ao masculino e ao feminino, incorporando à sua subjetividade os papéis sociais determinados para cada um dos sexos. Essa introjeção de valores acontece na socialização, através da 'inculcação' do habitus. De acordo com Bourdieu (2001), “o habitus é, concomitantemente, um sistema de esquemas de produção de práticas e um sistema de esquemas de percepção e apreciação das práticas. E, nos dois casos, suas operações exprimem a posição social em que foi construído" (p. 158).

É possível identificarmos, tanto na vida prática como na literatura que trata sobre a categoria gênero, a existência de alguns discursos que legitimam e justificam a constituição e a hierarquização dos homens e do masculino em relação às mulheres e ao feminino. Estes discursos apresentam um caráter de verdadeiros sistemas de crenças que atribuem características diferentes a cada um dos sexos. A partir destas atribuições, são determinados os direitos, os espaços e as atividades pertinentes a cada sexo. Historicamente, esses discursos encontram-se nas mais diversas áreas, dentre elas: na mitologia, na religião e nas ciências.

Puleo (2004), por exemplo, registra a presença dos discursos que legitimam essa desigualdade no ramo das ciências. Para ilustrar a proposição, a autora reporta-se à exclusão das mulheres da cidadania no momento da instauração das democracias modernas. No período em epígrafe, médicosfilósofos se fundamentaram, para deixá-las à parte desse processo, na teoria da debilidade cerebral feminina e, também, nos preceitos da Higiene, que prezavam pela dedicação integral das mulheres à maternidade.

Os estudos da autora, em análise, indicam que a filosofia é, também, uma ciência que, ao longo de sua história, em muitos casos, serviu para justificar a desigualdade entre os sexos. Contudo, a filosofia, por seu potencial emancipatório e sua força crítica, apresentase como uma ciência que tem a capacidade de impugnar, colocar em questão e, até mesmo, mudar essa relação injusta. Referenciada por esta visão, traça uma semelhança entre a história oficial da filosofia e a história oficial em geral:

Quando há um discurso profundamente misógino ou sexista em filosofia é porque paralelamente existe um discurso feminista nessa mesma época. Isso é muito interessante porque a história oficial 
da filosofia é como a história oficial em geral: uma história de vencedores (PULEO, 2004, p. 16).

Outra forma de manter os estereótipos comportamentais, segundo Silva (2005), é através dos livros didáticos, pois são através dos documentos escritos que são repassadas e ensinadas as maneiras corretas de comportamento social. Ao analisar um livro didático, o autor, em discussão, percebeu que as imagens e a forma pela qual os fatos históricos foram abordados reforçam o enquadramento da mulher ao âmbito privado. As imagens presentes nos livros analisados sempre enfocavam as mulheres em situação de subordinação, realizando trabalhos domésticos, cuidando de filhos ou em situação de consumo.

No setor produtivo em análise, percebemos que as construções simbólicas sobre o que é ser mulher e as características inerentes a esta condição, em muitos casos, determinam as atividades que podem ou não ser desenvolvidas pelas mulheres neste ramo produtivo. Às mulheres, na maioria das obras pesquisadas, cabem as atividades vinculadas à limpeza e aos serviços que requerem maior destreza, cuidado e sutileza, características cultural e socialmente vinculadas às mulheres. Tal fato é ratificado pelo depoimento do encarregado de uma das obras estudadas:

Há atividade que as mulheres têm um desenvolvimento melhor que o dos homens? A resposta é a mesma que você já sabe, que os outros homens, com certeza, já deram (risos), porque não tem uma outra. Pra falar a verdade, não tem. Mas, além da limpeza, tem uma outra que 'elas se destaca' melhor que os homens, é o rejuntamento. Elas rejuntaram muito. A gente tinha muita cerâmica pra fazer rejunte, colocamos elas no rejunte e elas fizeram um rejuntamento excelente. Bem melhor, mas bem melhor do que o dos homens. Nessa fase do acabamento, do rejunte, elas são bem melhores. Eu coloquei elas pra fazer e elas fizeram muito bem, desenvolveram muito bem. Homens que eu coloquei pra fazer, não fizeram. Eu tive que desfazer, tirar do local, porque não tava dando certo, o serviço estava de péssima qualidade e elas não, fizeram $e$ fizeram com ótima qualidade (Samuel, Encarregado, 33 Anos).

Em decorrência desse tipo de pensamento, muitas vezes, as mulheres inseridas neste setor têm seu campo de atuação profissional limitado. Inclusive, em alguns casos, contraditoriamente, serviços que requerem do trabalhador ou trabalhadora características que foram culturalmente vinculadas às mulheres - tais como o cuidado e a atenção são realizados pelos homens. A título de exemplo, podemos citar o trabalho em altura $^{10}$, que apesar de em sua regulamentação não existir restrição para sua execução por mulheres, na prática, alguns discursos construídos socialmente legitimam a incapacidade das mulheres para este tipo de serviço:

O trabalho em altura é um trabalho muito delicado, que exige, realmente, mais atenção e por elas serem mulheres, a gente coloca elas para trabalhar em locais mais baixos, em locais que não seja para subir em andaime (Samuel, Encarregado, 33 Anos).

Em contraposição a esta ideia, convém trazer à discussão o pensamento de Blay 
(2002). Essa estudiosa assevera que, no que se refere ao aspecto biológico, os seres humanos assemelham-se aos outros mamíferos, ou seja, podem ser machos ou fêmeas, sendo que a diferença entre ambos é restrita.

Segundo a autora supracitada, no concernente aos 'imperativos biológicos' relacionados, de um modo geral, aos homens $\mathrm{e}$ às mulheres, existem apenas quatro aspectos de diferença entre ambos, a saber: somente o homem tem a capacidade de fecundar; só a mulher pode menstruar, gestar e amamentar. Além dessas quatro funções reprodutoras básicas, segundo a estudiosa em epígrafe, nenhuma outra diferença existente entre os sexos estaria posta de forma imutável, de acordo ou segundo as linhas sexuais.

Nesse sentido, a falta de habilidade ou impossibilidade para execução de alguns serviços não, necessariamente, encontram-se atreladas ao sexo. Tão logo, acreditamos ser plenamente possível, por exemplo, um homem apresentar dificuldade para trabalhos em altura, enquanto uma mulher o executa de forma exitosa.

Na altura, elas já têm um pouco de dificuldade para trabalhar. Hoje, se eu colocar elas pra trabalhar no telhado, eu acho que elas não têm coragem de ir lá não, assim como tem homem que também não vai (Josué, Encarregado, 26 Anos).

Já fiz trabalho em altura, a gente põe o cinto e faz. Eu fiz acima de dois metros, usei o cinto e fiz. Tem até foto eu usando o cinto de segurança. Eu fazia as mesmas funções dos homens (Ana, Pedreira, 34 Anos).

Através da pesquisa de campo, percebemos, ainda, que algumas mulheres desempenham com louvor tarefas que, na construção civil, são, majoritariamente, atribuídas aos homens. O depoimento de um contratante entrevistado sobre o desempenho de uma pedreira contratada para uma de suas obras ratifica esta premissa:

Essa mulher, eu nunca vi essa mulher parada. Esta ai, essa mulher é um exemplo do serviço braçal masculino. Ela 'trepou' em andaime, fez massa, ela foi uma mulher que, aqui na obra, atingiu o patamar de 150 horas de tarefa, coisa que poucos homens ganharam. Então, o salário dela que é coisa de 800 reais, mais ou menos, passou para 1200, 1300 reais. Por quê? Porque ela participava de tarefas que eu só dava para homens (Moisés, Contratante, 54 Anos).

Um aspecto interessante suscitado no depoimento de uma das entrevistadas referese ao desgaste físico causado pelo trabalho doméstico e pelas tarefas tidas femininas, tais como cozinhar e lavar roupa. Relata a trabalhadora:

Trabalho pesado foi quando eu trabalhei em trabalho de mulher. Até hoje, eu tenho pesadelo com as panelas pesadas, eu levantando as panelas pesadas. Porque cozinheira é cozinheira, não tem esse privilégio de dizer: 'essa panela tá muito pesada, tá muito quente'. De jeito nenhum, a cozinheira tem a obrigação de fazer (Maria, Servente, 42 Anos).

Convém assinalar, conforme indicam Sorj, Fontes e Machado (2007) que as recentes mudanças ocorridas nas estruturas familiares e no mercado de trabalho agravaram a capacidade das famílias de lidarem com as 
exigências conflitantes do trabalho remunerado e do trabalho doméstico. Para as autoras, as últimas décadas, foram marcadas por uma importante transformação na composição sexual do mercado de trabalho e nas práticas de conciliação entre trabalho e responsabilidades familiares. $\mathrm{O}$ modelo tradicional deu espaço ao modelo de conciliação, no qual as mulheres permanecem como as principais responsáveis pelos cuidados familiares, apesar de sua inserção no mercado de trabalho.

No decorrer da pesquisa, verificamos que a realidade vivenciada pelas trabalhadoras da construção civil, no que se refere ao desafio de responder às demandas do trabalho doméstico e do trabalho remunerado, não é diferente do que indicam as autoras supracitadas. Considerável número de mulheres vivencia o modelo de conciliação. Elas, após, e em alguns casos, antes e depois de sua cansativa jornada de trabalho na construção civil, precisam dar conta dos afazeres domésticos e dos cuidados com os filhos, conforme demonstram as falas de algumas trabalhadoras:

Toda vida eu chego em casa, na semana, ai eu faço o básico. Se tiver janta, eu ajeito minha janta, esquento minha janta, lavo a louça, passo uma vassoura na casa, pronto...ai tomo um banho, vou assistir. Quando é no final de semana, ai eu lavo a roupa maior, colcha, rede, a farda, tudo! Na semana, para não ficar muito, eu vou lavando a roupa que eu vou vestindo no dia-a-dia. Faço uma comida, um feijão que dê para colocar na geladeira, dois ou três dias! É isso dá o suficiente, um pouco do trabalho e um pouco de casa, apesar da gente viver mais no trabalho (Maria, Servente, 42 Anos).

\begin{abstract}
A gente já deixa a comida ali guardada, 'né'? Pra quando chegar em casa só esquentar. Mas, às vezes, assim, quando não tem feito, eu peço já feito. E tem uma pessoa que cuida dos meus filhos, ela vai todo dia! Aí, de manhãzinha, antes de eu sair, eu já tenho que deixar o mingau da minha 'bebezinha' feito. Eles sentem muito minha falta, quando eu chego em casa é aquela carreira pra cima de mim. No final de semana, eu coloco a roupa pra lavar na máquina, arrumo a casa e, aqui e acolá, o meu menino de 11 anos também ajuda (Isabel, Pedreira, 35 Anos).
\end{abstract}

Por fim, foi possível registrar que, além do modelo de conciliação, praticamente predominante entre as entrevistadas, o modelo de delegação - cujo trabalho doméstico é delegado a outrem, geralmente outras mulheres. Percebemos que, em alguns casos, as trabalhadoras precisam delegar suas atividades domésticas e cuidados com os filhos a outras pessoas, sejam elas da própria família - filhas, noras, sogras, mães ou tias ou pessoas fora do vínculo familiar, remuneradas para esse trabalho.

\section{Considerações Finais}

Por meio do estudo realizado, buscamos evidenciar os principais aspectos das relações de gênero e trabalho que permeiam o trabalho de homens e mulheres na construção civil de Fortaleza (CE).

$\mathrm{O}$ incentivo por parte dos construtores para a entrada feminina, nesse ramo, não ocorre de forma despretensiosa. $\mathrm{Na}$ realidade, para as empreiteiras, essa inserção apresenta objetivos bem definidos: redução dos custos das obras e aumento da qualidade do produto final.

Assim, podemos dizer que a força de 
trabalho feminina, anteriormente utilizada apenas para limpeza das obras após sua conclusão, ganhou novas atribuições. Elas passaram a realizar alguns serviços, antes indicados aos homens, que são de fácil execução, mas que demandam tempo e habilidade manual, tais como assentar e rejuntar a cerâmica. Essa mudança na produção favorece a redução do período de execução e dos custos das obras e, ainda, o aumento da qualidade do serviço, pois as atividades que as mulheres passaram a desempenhar, recebendo o mesmo salário antes pago apenas pela limpeza da obra, quase sempre requerem cuidado, atenção e minúcia, características socialmente relacionadas ao feminino.

Percebemos que as construtoras, assim como a gestão municipal e estadual em suas empreitadas, também utilizam a mão de obra feminina com o intuito de obter promoção e visibilidade social, uma vez que o fomento à entrada das mulheres em ramos profissionais tradicionalmente masculinos traz consigo a ideia de quebra de preconceitos e de promoção da mão de obra feminina.

Já para as mulheres, o ingresso neste ramo é motivado, principalmente, pela oportunidade de inserção no mercado de trabalho formal e pela melhor remuneração paga por esse segmento. A maioria delas sente orgulho por exercer uma atividade que, até pouco tempo, era estritamente vinculada ao universo masculino.

O trabalho na construção civil viabilizou o acesso destas trabalhadoras aos bens e aos serviços que, em um passado bem próximo, constituíam-se inalcançáveis para elas. Muitas delas destacam, ainda, a independência financeira que tiveram em relação aos seus maridos e companheiros.

No decorrer desta investigação, pudemos constatar que a maioria das mulheres encontra-se na função de servente, executando, principalmente, serviços de acabamento. Mas nos deparamos, também, com mulheres pedreiras, realizando as mesmas tarefas que os homens e tendo o seu trabalho muito bem visto e aceito por parte de seus contratantes.

Todavia, não registramos nenhum caso em que uma mulher estivesse no cargo hierárquico superior da produção, mestre de obras, embora, algumas delas, pelo depoimento dos próprios contratantes, tenham plenas condições para ascender profissionalmente.

Não constatamos diferença salarial em decorrência do sexo, contudo a maioria das mulheres, conforme expresso anteriormente, encontra-se na função cuja remuneração é a menor do setor, ou seja, elas são classificadas como serventes. Concernente a este aspecto, existe, ainda, a não aceitação de alguns trabalhadores em relação à política de remuneração igual para funções iguais. Parte dos homens não acha justo que as operárias, que exercem sua mesma função, recebam o seu mesmo salário, pois sob o ponto de vista deles, elas não executam as mesmas atividades que eles.

Percebemos que, no processo de terceirização de serviços que ocorre no setor, as mulheres são as maiores vítimas das irregularidades realizadas por empresas terceirizadas. Essas empreiteiras, em alguns casos, utilizam-se de alguns artifícios para não registrar o trabalho feminino ou para fazer com que as mulheres abram mão de alguns dos seus direitos. Um fato recorrente são as obras de curto prazo, nas quais a empresa terceirizada 'aconselha' às mulheres a não reivindicar o registro na carteira para não 'sujá-la' com um serviço de curta duração.

Destacamos que o trabalho feminino neste ramo é marcado pela divisão sexual do trabalho. A constituição social do que é ser homem e do que é ser mulher influencia, diretamente, na diferenciação das atividades delegadas aos trabalhadores $\mathrm{e}$ às 
trabalhadoras nos canteiros. Geralmente, às mulheres são direcionados os trabalhos considerados mais leves e que requerem características atribuídas ao feminino como, por exemplo, a colocação e rejuntamento da cerâmica e a limpeza. Já os homens são requisitados para trabalhos que necessitam de mais força física e coragem, tais como, escavações, concretagem e trabalho em altura.

Outro aspecto que permeia o trabalho das mulheres na construção civil vincula-se à divisão do trabalho doméstico. As trabalhadoras, em sua maior parte, ainda são as principais responsáveis pelos afazeres domésticos e cuidado com os filhos. Em alguns casos, verificamos que as operárias delegam suas atribuições domésticas a outras mulheres, geralmente, às suas mães, sogras, filhas ou irmãs.

Por fim, compreendemos que na construção civil, espaço culturalmente destinado aos homens, a presença das mulheres não é isenta de conflitos e de questionamentos. Todavia, sob nosso ponto de vista, os canteiros de obras são sim lugares para atuação profissional das mulheres, contudo, reconhecemos que muitas mudanças precisam acontecer para que estas possam exercer de forma digna sua profissão. Nesse sentido, acreditamos serem necessárias alterações nas práticas e nos valores dos atores sociais, além de serem repensados os papéis que foram social e historicamente atribuídos aos homens e às mulheres com base na hierarquia de gênero.

1 Pesquisa realizada em três obras da cidade de Fortaleza, a saber: uma é a construção de um equipamento público municipal, outra de um equipamento público estatal - ambas utilizam a mão de obra feminina na produção, tanto na função de pedreiras como serventes. Por último, temo uma obra de construção de um residencial, neste caso, especificamente, as trabalhadoras realizam apenas o trabalho de limpeza da obra e o rejuntamento da cerâmica. entrevista.

2 Informações obtidas através de

3 Este é um nome fictício a fim de resguardar a identidade do informante. Ressaltamos que utilizaremos nomes bíblicos sempre que precisarmos fazer referência às falas dos entrevistados e das entrevistadas desta pesquisa. A escolha por nomes bíblicos se deu em decorrência da forte religiosidade expressa pelos trabalhadores das obras analisadas.

4 Refere-se, neste caso, ao gasto com os homens para construção dos prédios e com as mulheres para executar a limpeza dos mesmos.

5 A Pesquisa Mensal de Emprego PME, implantada em 1980, produz indicadores para o acompanhamento conjuntural do mercado de trabalho nas regiões metropolitanas de Recife, Salvador, Belo Horizonte, Rio de Janeiro, São Paulo e Porto Alegre. Trata-se de uma pesquisa domiciliar urbana realizada através de uma amostra probabilística, planejada de forma a garantir os resultados para os níveis geográficos em que é realizada.

$6 \quad$ Média das estimativas mensais.

7 Informação divulgada em site especializado na Internet: http://blog.mte.gov.br/?p=965.

8 Período referente ao intervalo de tempo entre 2000 e 2010.

9 Sindicato que representa os empresários da construção civil do Estado do Ceará. Tentamos contato com esta instituição, 
mas não tivemos êxito. Enviamos e-mail conforme fomos orientados em um dos contatos telefônicos, realizamos várias ligações, mas não conseguimos falar com a diretora indicada como responsável pelo projeto.

10 De acordo com a NR-35, do Ministério do Trabalho e Emprego, o trabalho em altura é toda atividade executada acima de dois metros do nível inferior, onde haja risco de queda. A NR-35 estabelece que o empregador deverá promover um programa para capacitação dos trabalhadores para a realização de trabalho em altura. Trabalhador capacitado para o trabalho em altura é aquele que foi submetido e aprovado em treinamento, teórico e prático, com carga horária mínima de oito horas. O conteúdo deve, no mínimo, incluir normas e regulamentos aplicáveis, dentre eles ao trabalho em altura; análise de risco e condições impeditivas; equipamentos de Proteção Individual e condutas em situações de emergência.

\section{Referências}

BERGER, Peter, LUCKMANN, Thomas. A construção social da realidade. Petrópolis: Vozes, 1978.

BLAY, Eva Alterman. (Org.) Igualdade de oportunidade para as mulheres: um caminho em construção. São Paulo: Humanitas/FFLCH/USP, 2002.

BOURDIEU, Pierre. O poder simbólico. 4. ed. Rio de Janeiro: Bertrand Brasil, 2001.

A dominação masculina. Rio de Janeiro: Bertrand Brasil, 2007.

FOUCAULT, Michel. A ordem do Discurso. São Paulo: Loyola, 2005.
Microfísica do poder. Rio de Janeiro: Graal, 2007.

INSTITUTO BRASILEIRO DE GEOGRAFIA E ESTATÍSTICA - IBGE. Síntese de indicadores sociais - 2009 (Estudos e Pesquisas - Informação Demográfica e Socioeconômica $-\mathrm{n}^{\circ} 27$ ). Rio de Janeiro: 1990.

- Síntese de indicadores sociais 2009 (Estudos e Pesquisas - Informação Demográfica e Socioeconômica $-\mathrm{n}^{\circ} 27$ ). Rio de Janeiro: 2010.

Pesquisa mensal de emprego (Mulher no mercado de trabalho: perguntas e respostas - boletim especial -Dia Internacional da Mulher). Rio de Janeiro: 2012 .

LOBO, Elizabeth Souza. A Classe Operária tem dois sexos. São Paulo: Edit. Brasiliense, 1991.

LOURO, Guacira Lopes. Uma leitura da História da Educação sob a perspectiva do gênero. Teoria \& Educação. n. 6, p. 53-67, 1992.

MINISTÉRIO DO TRABALHO E EMPREGO - MTE. Promoção de igualdade de oportunidades e de combate à discriminação no trabalho. Brasília: 2009.

Promoção de Igualdade de Oportunidades e de Combate à Discriminação no Trabalho. Brasília: 2011.

OSTERNE, Maria do Socorro Ferreira. Família, Pobreza e Gênero: O Lugar da Dominação Masculina. Fortaleza: EDUECE, 2001.

Violência nas relações de gênero e cidadania feminina. Fortaleza: EDUECE, 2008. 
PULEO, Alicia. Filosofia, gênero $\mathbf{y}$ pensamiento crítico. España: Universidad de Valladolid, 1999.

SAFFIOTI, Heleieth. Inserção da mulher na força de trabalho brasileira: períodos de prosperidade e períodos de crise econômica no Brasil: 1872-1982. Rio de janeiro: In: XVI CONGRESSO LATINO - AMERICANO DE SOCIOLOGIA, 1986.

Moderna, 1987.

O poder do macho. São Paulo:

. Gênero, patriarcado, violência. São

Paulo: Fundação Perseu Abramo, 2004.

. Rearticulando gênero e classe social. In: COSTA, Albertina de Oliveira; BRUSCHINI, Cristina. (Orgs.). Uma Questão de gênero. São Paulo; Rio de Janeiro: Rosa dos Tempos, 1992, p. 183 - 215.

SCOTT, Joan. O gênero como uma categoria útil de análise histórica. Educação e Realidade, n.2, p. 71 - 99, 1990.

. Género: una categoría útil para los estudios históricos? In: LAMAS, Martha. (Org.). El género: la construcción cultural de la diferencia sexual. Cidade do México: PUEG, 1997, p. 265 - 302.

A cidadã paradoxal: as feministas francesas e os direitos dos homens. Florianópolis: Editora Mulheres, 2002.

SILVA, Severino Vicente da. Imagens da mulher em um livro didático. In: MARTÍN, Márcia Castillo; OLIVEIRA, Suely (Orgs.). Marcadas a ferro. Brasília: Secretaria Especial de Políticas para Mulheres, 2005, p.154 - 158 . 